\title{
La participación en línea en la esfera pública Las ambigüedades del afecto ${ }^{1}$
}

\section{Public sphere participation online The ambiguities of affect}

\section{PETERDAHLGREN}

peter.dahlgren@kom.lu.se - Lund University, Suecia.

Fecha de recepción: 27 de febrero de 2018

Fecha de aceptación: 28 de marzo de 2018

\section{RESUMEN}

El punto de partida de este artículo consiste en la creciente atención al afecto como aspecto importante de la participación política, en particular en el contexto del rol de los medios sociales en la democracia y en las esferas públicas. El abordaje recopila una amplia variedad de análisis e investigaciones sobre la participación, las esferas públicas y el afecto, con el objetivo de destacar logros importantes, problemas y ambigüedades. Al abordar este grupo de temas relacionados, no encontramos un conjunto de conocimientos acumulativo y unificado, sino facetas de diversas tradiciones. Si bien esto puede presentar ciertas dificultades, al mismo tiempo puede alentarnosareflexionar sobrenuestraspropias premisas. La primera parte trata el concepto de participación. Allí se expone una visión estricta que considera a la participación como una intervención, por pequeña que sea, en las relaciones de poder. Mientras que en un segundo momento se explora la noción de afecto: se lo encuadra dentro del campo de fuerza de la racionalidad y la emocionalidad, las cuales han sido ideas centrales en la teoría de la democracia. La tercera parte del artículo se enfoca en el entorno en línea, en particular en los medios sociales, destacándose algunas delas ambivalencias persistentes en la participación en línea y su relevancia para el afecto.Laparte final ofrece unas breves reflexiones sobre el afecto y el populismo, incluido el tema de los caminos públicos legítimos hacia el conocimiento.

PALABRASCLAVE: esferas públicas digitales, afecto y politica, participación política, politica en línea, compromiso cívico.

\section{ABSTRACT}

The point of departure of this article is the growing attention to affect as an important aspect of political participation, particularly in the context of online media's role in democracy and public spheres. The approach is to pull together a broad range of research and analysis on participation, public spheres and affect, with the aim of highlighting important gains as well as issues and ambiguities. In addressing this cluster of interrelated concerns, we do not find a cumulative body of unified knowledge, but rather strands from various traditions. While this may present some difficulties, it may serve also to encourage us to reflect on our own premises. The first section deals with the concept of participation, arguing for a robust view that sees it an intervention, however small, into power relations. The second section pursues the notion of affect, framing it within the force-field of rationality and emotionality that has been a traditional motif within democracy theory. The third section focuses on the online environment, in particular social media, highlighting some of the lingering ambivalences of online participation and their relevance for affect. The final section offers some brief reflections on affect and populism, including the theme of legitimate public pathways to knowledge.

KEYWORDS: digitalpublicspheres, affectandpolitics, political participation, online politics, civic engagement.

1 Una versión de este artículo será publicada en inglés durante 2018 con el título: Public sphere participation online: the ambiguities of affect. International Journal of communication, 12. 


\section{EL PANORAMA ACTUAL}

Los debates sobre la contribución de Internet a la esfera pública y a la democracia comenzaron poco después de que la presencia en línea se empezó a convertir en un fenómeno masivo, a mediados de la década de 1990. Hoy, más de dos décadas después, sin duda no estamos cerca de llegar a un consenso, pero la mayoría acordaría que la algarabía optimista inicial se ha disipado. Los escépticos como Mozorov (2011) encuentran abundantes evidencias de que no deberíamos tener mucha fe en el potencial de Internet para salvar o incluso mejorar la democracia. Al mismo tiempo, otros señalan con entusiasmo las circunstancias en las que la intervención política en línea tiene un claro efecto positivo (Castells, 2012). Más recientemente, Margetts y otros autores (2016) adoptan una postura cautelosamente positiva, pero argumentan quelos medios sociales, si bien facilitan la acción colectiva mediante "actos de participación diminutos” (p. 199), también alteran la dinámica de la democracia e introducen un nuevo "pluralismo caótico" (p. 198), cuyas consecuencias aún no podemos prever. Hemos llegado a comprender que no existe un efecto único y unívoco: el uso y las consecuencias de la red para fines políticos, así como para otros fines, siempre dependen de varios factores ${ }^{2}$.

Por lo tanto, en este punto no se trata de llegar a una conclusión definitiva, sino de seguir explorando y analizando los cambios constantes en la sociedad y en la política junto con las continuas transformaciones del panorama digital. En lo que respecta a los medios sociales, debemos tener en cuenta que este término engloba una amplia variedad de plataformas y ofrecimientos diferentes, que pueden usarse para diversos objetivos. En algunos contextos, es necesario diferenciarlos. En general, las interfaces medios-sociedad son enormemente complejas, pero la investigación subraya cada vez más la profundidad con que los medios contribuyen a la transformación social. En los últimos años, surgió la noción de mediatización, que plasma este enfoque (por ejemplo: Hepp, 2013; Hjarvard, 2013; Lundby, 2014; el número de Communication Theory, 2013; Lunt \& Livinstone, 2014). Se argumenta que la interacción de los medios con cada sector específico de la sociedad y de la cultura altera de alguna manera su funcionamiento y que, por extensión, transforma a la sociedad en general, aunque este no es en absoluto un desarrollo unidireccional ni determinista. En la actualidad, la red afecta todas las fases de la vida personal, organizativa e institucional. Esto significa que se ha convertido en una fuerza dominante en la construcción del mundo moderno contemporáneo (Couldry \& Hepp, 2016).

Dentro de este amplio horizonte, debemos comprender el significado delos medios digitales en las esferas públicas y en la participación política. Hoy hace-

2 Aquí uso las nociones de red y de Internet de manera amplia: incluyo toda la infraestructura, plataformas y medios sociales digitales, también todos los dispositivos estáticos y móviles del mundo en línea. 
mos política de diferentes formas, aunque no hay una ruptura total con el pasado. Por ejemplo, la televisión continúa siendo una institución importante en la esfera pública. Las prácticas políticas y las estructuras institucionales cambiantes que surgieron con Internet modificaron la dinámica de la democracia, pero aún nos encontramos totalmente inmersos en ella. Por lo tanto, carecemos del lujo de la retrospectiva. Además, nuestros marcos conceptuales de referencia y nuestras herramientas de análisis siguen evolucionando. En consecuencia, en los últimos años, el afecto ha surgido como foco de atención de los debates sobre la política y la participación. Esto constituye la continuación de un giro, en las últimas décadas, hacia la exploración profunda del aspecto emocional de la política, tal como se observa en los estudios culturales (por ejemplo, van Zoonen, 2005), en la filosofía política (Hall,2005) e incluso en la comunicación ylas ciencias políticas (por ejemplo, Coleman, 2014). En particular, las ciencias dela comunicación han comenzado a abordar activamente el afecto yla política en relación con Internet (véase, por ejemplo, Papacharissi, 2014).

En esta discusión, quiero seguir esta trayectoria definiendo conceptualmente las nociones de participación y afecto. Además, quiero esclarecer ciertos atributos clave del mundo en línea conocido, algo que a veces damos por sentado, pero que, en mi opinión, resultan aspectos o contingencias que definen la experiencia en línea, sobre todo en lo que respecta a las esferas públicas y a la formación de la subjetividad y el afecto. En este artículo se recopila una amplia variedad de análisis e investigaciones sobre la participación, las esferas públicas y el afecto. Mi objetivo es destacar lo que considero logros importantes, así como problemas y ambigüedades que debemos enfrentar, también expreso mi propio punto de vista respecto de estas problemáticas. Al abordar este grupo de temas relacionados, no encontramos un conjunto de conocimientos acumulativo y unificado, sino facetas de diversas tradiciones. Si bien esto puede presentar ciertas dificultades, al mismo tiempo puede alentarnos a reflexionar sobre nuestras propias premisas y puntos de partida. Es posible progresar incluso especificando los problemas y yuxtaponiendo horizontes contrastantes.

Este trabajo presenta tres partes principales. Comienzo con una discusión sobre la participación, que incluye lo que se puede considerar como predisposición subjetiva: el compromiso. Destaco que la participación, en cierto punto, debe plasmar un encuentro con las relaciones de poder. En la segunda parte abordo el afecto. Lo encuadro dentro del campo de fuerza de la racionalidad yla emocionalidad, las cuales han sido ideas centrales en la teoría dela democracia. La tercera parte se enfoca en el entorno en línea, en particular en los medios sociales. Allí subrayo algunas de las ambivalencias persistentes en la participación en línea y su relevancia para el afecto. Finalmente, el artículo concluye con unas breves reflexiones sobre el afecto y el populismo. Estos dilemas incluyen, en particular, los caminos públicos legítimos hacia el conocimiento. 


\section{LOS DETALLES DE LA PARTICIPACIÓN}

\subsection{El poder y los parámetros}

El concepto de participación deriva de diversos campos de las ciencias sociales. Por lo tanto, es una noción un tanto fluida, en particular, dentro de las ciencias de la información y las comunicaciones (para un desarrollo exhaustivo, consultar: Carpentier, 2011). Un punto inicial para aprehender el concepto de participación se encuentra en la noción de lo político. Esto se refiere al potencial, siempre presente, de antagonismos y conflictos de interés colectivos en todas las relaciones y entornos sociales (Mouffe, 2013). Esta es una noción más amplia que la de política, la cual a menudo se refiere a contextos institucionales más formalizados. Por lo tanto, podemos decir que la participación implica intervención en lo político, en las relaciones de poder, independientemente de cuán remotas (o mediadas) sean. Siempre involucra algún tipo de confrontación o lucha, aunque solo sea una discusión. Sin duda, algunos aspectos de lo político forman parte de la política electoral e implican toma de decisiones o elecciones, pero es fundamental que tengamos en cuenta este sentido amplio y extraparlamentario de lo político. Además, debemos diferenciar, en los contextos de medios, a la participación del simple acceso o de la mera interacción. A menudo estos se confunden erróneamente con la participación. Sibien son necesarios, no resultan suficientes, como insiste Carpentier (2011).

Así, lo político puede surgir discursivamente y aparecer en cualquier dominio de la actividad social y cultural, aun en el consumo y el entretenimiento (y encontramos innumerables ejemplos de ello en los medios sociales). Para la verdadera participación, el contexto siempre es significativo. Es muy diferente si, en las democracias occidentales, hablamos por ejemplo sobre la intervención en debates de la esfera pública, el sufragio en las elecciones o las protestas callejeras. Si pasamos a un entorno de resistencia contra regímenes autoritarios, las personas enfrentan peligros reales y arriesgan sus vidas, lo cual da otro significado a la participación. No existe una noción generalizada y universal de la participación. Siempre ocurre en circunstancias específicas y se manifiesta en prácticas concretas.

Las relaciones y las estructuras de poder no se refieren solo a manifestaciones obvias como el Estado, con su sistema legal, su ejército o policía; o como el sector corporativo, con su poder político y económico; sino también a formas culturales y discursivas, es decir, aquello que refiere al control o la influencia sobre entornos simbólicos. Asimismo, es importante mencionar que el poder constituye tanto el poder de (posibilidad) como el poder sobre, en forma de coerción, limitación o influencia. Por lo tanto, la participación en sí misma es una expresión de cierto grado de poder (posibilidad), por mínimo que sea.

Cualquier ejemplo concreto de participación en entornos democráticos, al menos nominalmente, puede analizarse según varios parámetros obvios. Uno 
de estos aspectos, que no son exhaustivos, es el grado de dificultad. Es decir: ¿la participación es "fácil" de lograr o se enfrenta a mecanismos de exclusión? Otro parámetro es si la participación se inserta de alguna forma en una acción colectiva, o si es de carácter individual y aislado. Esta distinción se ha vuelto más relevante en la era digital, tal como se detalla en los próximos apartados.

Dos parámetros más a tener en cuenta son los que denomino horizonte y periodo. El horizonte se relaciona con el grado de participación de las personas "en los medios" o en un dominio social mayor "a través de los medios" (Carpentier, 2011). El primer caso, en general, se asocia con el entretenimiento y la cultura popular, mientras que el segundo es típico de las noticias y los temas de interés público. Sin embargo, la ficción puede generar participación política, y el periodismo y el debate políticos pueden constituir un mero espectáculo (agradable). Por su parte, el periodo se refiere a la duración de la participación: ¿se sostiene en el tiempo o es a corto plazo? Esto puede ser de crucial importancia. A veces, una intervención breve es adecuada desde el punto de vista estratégico, pero los observadores notan que con demasiada frecuencia la atención se dispersa o la participación pierde impulso y se disipa. Por ejemplo, cuando una protesta inicial no logra intervención política continua. Finalmente, aunque no es estrictamente un parámetro, debemos considerar el resultado: ¿Qué se logró? ¿O cuáles fueron las consecuencias de la participación?

A partir de lo descrito, y teniendo en cuenta la utilidad de estos parámetros para evaluar la participación, a continuación retomo y me detengo en algunos aspectos particulares ligados a esta cuestión.

\subsection{Prerrequisitos cívicos}

Más allá de los parámetros externos antes mencionados, también es importante considerar los recursos y la preparación de los ciudadanos. En cierto sentido, son "prerrequisitos" cívicos para la participación que pueden trasladara la personas de la "política del ser" a "ser políticos", como expresa Fenton (2016). En un trabajo anterior (Dahlgren, 2009), argumento que si la participación plasma algún tipo de comunicación o acción política, el compromiso se puede considerar como la disposición subjetiva necesaria que antecede a la participación y, en cierta forma, la prepara. El compromiso político depende así de lo que se denomina culturas cívicas: los recursos culturales que fomentan o impiden el compromiso (y, por extensión, la participación), según las circunstancias y las fuerzas involucradas.

Las culturas cívicas consisten en ciertas dimensiones tales como el conocimiento relevante, los valores democráticos, los mínimos niveles de confianza entre los ciudadanos, los espacios comunicativos (en particular, los digitales) y las prácticas con algún grado de eficacia. En conjunto, estos factores pueden fomentar un sentido de identidad cívica: la autopercepción de que uno es un actor político con poder. Sin embargo, quienes tienen poder sobre las cultu- 
ras cívicas pueden contribuir en gran medida a debilitarlas y bloquearlas. Por lo tanto, el destino de estos recursos culturales a menudo resulta un tema de conflicto político (por ejemplo, la censura puede bloquear el acceso al conocimiento). Sin ese acceso a los recursos de las culturas cívicas, la intervención de los ciudadanos en lo político se debilita.

En resumen, el punto es quela participación política nunca comienza como tabula rasa: siempre está condicionada por circunstancias externas y, además, por los recursos de los ciudadanos. Las relaciones de poder influencian a todos estos factores de diversas maneras. En lo que respecta a los medios, podemos examinar cómo fomentan o dificultan las culturas y el compromiso cívico. Como ya resulta claro, yo promuevo una definición de participación ligada a los modos de intervención en las relaciones de poder, mientras que también destaco sus contingencias, sobre todo en lo que respecta a los prerrequisitos del compromiso subjetivo y a los recursos de las culturas cívicas. Esta definición y los alcances dados a la subjetividad nos llevan fácilmente a la noción de afecto.

\section{EL AFECTO, LOS SUJETOS Y LA POLÍTICA}

\subsection{El sujeto del afecto}

En los últimos años, la noción de afecto se ha vuelto más prominente. En las humanidades y en las ciencias sociales ha surgido un giro afectivo inspirado en Spinoza, entre otros (por ejemplo, Massumi, 2002; Gregg \& Seigworth, 2010). En las ciencias de la comunicación, Papacharissi (2014) recientemente incorporó y movilizó el término en el análisis de los medios sociales. Dicha autora sugiere que el término nos ayuda a analizar modos de compromiso político que se encuentran fuera de las expresiones de opinión formalizadas. Además, indica cómo el sentimiento político informe y espontáneo puede acumularse, pasar delolatentea lo manifiesto y dar una nueva forma al compromiso y a la participación. En términos sencillos, si la emoción es un estado en el que uno se encuentra, el afecto se relaciona con cómo se llegó allí. Asimismo, y como se discutirá a lo largo de este apartado, el afecto incluso puede referirse a estados de subjetividad colectiva.

Esta atención reciente al afecto puede situarse como parte de una visión intelectual ampliada, en la que las teorías sobre la idea del sujeto se han vuelto más expansivas. En la literatura en lengua inglesa, observamos un notable aumento en el interés por estos temas en las décadas de 1970 y 1980, dentro de la fase de expansión de los estudios culturales británicos (véase para un panorama general: Turner, 2002). Se tomaron muchos elementos de la teoría francesa, entre ellos, las (muy diversas) obras de interpretación lingüística de Freud por parte de Lacan, las teorías del discurso posestructuralistas de Foucault, la descentralización del significado de Derrida, la semiótica de Barthes y la combinación de psicoanálisis y feminismo de Kristeva. En la década de 1980, 
las perspectivas posmodernas transmitían un sentido del ser situado, reflexivo y compuesto. Todas estas corrientes contribuyeron a desafiar el modelo (masculino) del ser universal.

En la actualidad, los contextos como la globalización, el multiculturalismo y el poscolonialismo también influyen en cómo consideramos al sujeto. En paralelo, y a veces en relación con esto, hemos visto que el concepto de identidad ha sido el foco de interés de diversas disciplinas. Ciertamente, la identidad seha convertido en un tema familiar en las últimas décadas. El uso conceptual puede variar en diferentes tradiciones, pero la mayoría de los académicos consideran que la identidad se construye socialmente, en un proceso continuo en el que la interfaz, las circunstancias y las experiencias de las personas forman el sentido de quiénes son, tanto para sí mismas como para los demás. El sujeto, por otra parte, es un constructo analítico que tiende a significar una parte más fundamental del ser, el quién básico tras el trabajo deidentidad. Empero, para algunas tradiciones, incluso el núcleo del sujeto se considera un producto social.

Algunas de estas corrientes teóricas comenzaron a penetrar en las ciencias de la comunicación. En cambio, la corriente convencional de este campo continuó con los modelos psicológicos derivados de las ciencias sociales tradicionales, en los que los individuos en general se conciben en términos más bien de sentido común, que en ocasiones mantienen dimensiones conductistas. En tal sentido, la literatura que teoriza sobre el sujeto es amplia y comprende varias disciplinas. Incluso, un resumen acotado o un inventario extenso y complejo excedería los alcances de este artículo (véase una breve introducción de este tipo en: Elliott, 2008). Sin embargo, quisiera hacer mención a una síntesis temática que he realizado, a partir del horizonte abierto por las ciencias de la información, sobre algunas de las tradiciones mencionadas, generadoras según mi punto de vista de cuatro temas (Dahlgren, 2013). Estos temas pueden tener límites difusos, ya que no siempre se diferencian fácilmente. Aunque expresados en un lenguaje conceptual variable, indican gran parte de lo que distingue a una tradición de otra.

Los temas son: racionalismo, que plantea hasta qué punto nuestra subjetividad y nuestras acciones se guían por la razón o las emociones; reflexividad, un concepto que es central para la tradición del constructivismo social y señala cómo ajustamos y monitoreamos nuestras acciones en contextos sociales, y las consecuencias que esto acarrea; la transparencia, o más bien su carencia: aquí el elemento analítico decisivo es el inconsciente. La tradición freudiana y sus diversas ramas argumentan que no podemos acceder totalmente a nuestra propia subjetividad, no podemos entendernos a nosotros mismos del todo. La negación, la represión, la ira desplazada, el miedo no reconocido, etc. son partes inexorables de nuestra realidad interna. Y, finalmente, el tema de la contingencia; es decir, hasta qué punto nuestros contextos y circunstancias nos moldean como sujetos. Esta corriente intelectual se asocia principalmentecon 
varias ideas sobre cómo el discurso nos moldea y nos posiciona como sujetos.

En función de esta caracterización, no se necesita un gran salto analítico para entender que el afecto puede tener distintos significados y funciones en tradiciones con diferencias temáticas. Sobre algunos de estos aspectos nos detendremos en los próximos apartados.

\subsection{La dicotomía clásica: la racionalidad y la emocionalidad}

El tema del racionalismo nos ofrece un cómodo punto de ingreso a una discusión sobre el afecto, mientras que la cuestión de la transparencia (la perspectiva de un inconsciente operativo) también resulta muy relevante. Al considerar la participación en las esferas públicas, a menudo llegamos a preguntas básicas: ¿qué la facilita realmente, y cómo debemos comprender esa agencia? ¿Cómo es que las personas realmente dan el paso y actúan en relación con lo político? Comprometerse con algo implica no solo atención cognitiva y tal vez una postura normativa, sino también una intervención subjetiva, una dedicación del ser. Aquí existe una carga emocional: uno siente una opinión intensa sobre el asunto. Esto es el compromiso, y nunca puede reducirse a lo puramente racional. La intensidad y el grado de involucramiento pueden variar considerablemente. Cuando son fuertes, podemos hablar de pasión. El origen y el poder de la pasión tal vez se encuentren, hasta cierto punto, fuera del alcance de la mente consciente.

En la teoría democrática contemporánea, se enfatiza encarecidamente la racionalidad como el ideal normativo para la participación y la deliberación. Este modo comunicativo es, por supuesto, indispensable a veces, sobre todo cuando se acerca la toma de decisiones formal, como han afirmado los teóricos habermasianos. Sin embargo, insistir en esto como modelo general de las prácticas de participación puede resultar restrictivo para la subjetividad y su expresión, las cuales son centrales para la política (Dahlberg, 2014). Esa postura incluso puede tener consecuencias excluyentes: exigir un determinado género de comunicación formalizada que quizá no sea la forma de expresión más natural para todos los grupos sociales, y así contribuir a marginarlos y desempoderarlos.

La postural liberal tradicional que enfrenta a la racionalidad con la emoción es contraproducente desde el punto de vista analítico, tal como varios han argumentado (véase Hall, 2005). Debemos aprehender la interconexión entre razón y emoción. En el fondo, las pasiones políticas siempre tienen razones, incluso si no siempre podemos acceder a ellas de inmediato. Existe una meta o un objeto que se valora. Por lo tanto, la pasión política, aun si en parte se fija en el inconsciente, no es ciega. Involucra cierto sentido del bien, de algo a lo que vale la pena aspirar, y a menudo también involucra cierta noción de cómo lograrlo (aun cuando las metas y los métodos siempre pueden cuestionarse). Las razones, por su parte, incorporan emociones. De la misma forma en que 
una pasión por algo implica que existe una razón para valorarlo, una razón para elegirlo sugiere al menos cierto grado de emocionalidad en la elección. Asimismo, incluso las conductas indeseables, como la violencia y la agresión, nunca son el resultado exclusivo de la pasión "pura": siempre existen razones también (aun si no son sostenibles en forma normativa).

Empero, al dejar paso a las emociones en el análisis del compromiso político, también dejamos ingresar una serie de problemas que no podemos ignorar. Entre los teóricos de la democracia existe un miedo comprensible a lo irracional. La historia está repleta de terribles ejemplos. El miedo, la ira, la negación, el odio y la venganza son valencias emocionales que pueden estimular el compromiso y causar conductas políticas destructivas.

La ausencia de autotransparencia total es, por supuesto, la premisa fundamental del psicoanálisis y de su visión sobre el inconsciente. Existen varias versiones del inconsciente, pero el modelo freudiano, con sus diversas revisiones y ramas, se ha convertido sin duda en el dominante (si bien existen abundantes disputas entre las diversas escuelas). La noción de que existen regiones opacas en nuestra psiquis contradice el ideal de autodominio y autocontrol, muy valorado en la visión del mundo racional. Sin embargo, nuestra comprensión y nuestro análisis pueden enriquecerse si aceptamos la dinámica, a veces difícil, entre la razón y la emoción. Para encontrar evidencia de esta interrelación no se necesita ser psicoterapeuta matriculado. Opino que una perspectiva sencilla de un inconsciente activo basada en el sentido común resulta suficiente. Básicamente, la política (y la subjetividad misma) se encuentran en medio de la distinción entre lo racional y lo emocional, y la participación en parte se afirma en las tensiones entre ellos.

\subsection{El afecto: configuraciones colectivas}

El vocabulario de las emociones y los sentimientos es impreciso y problemático, como subraya Frosh (2011), un psicólogo con amplios conocimientos sobre teoría social. Pero podemos comprender la importancia del afecto si consideramos quelo que moldea la participación es algo más poderoso que solo lasideas dentro dela cabeza de los individuos: la experiencia social. Porlotanto, el afecto implica el lado colectivo de la emocionalidad y deriva de las obras de varios autores específicos, como describe Papacharissi (2014). Una fuente que ella destaca es Raymond Williams y su noción de las estructuras de sentimiento. Para Williams, las estructuras de sentimiento expresan las corrientes culturales y los estados de ánimo vigentes en determinado momento histórico. Son implícitas e inconclusas, pero aun así pueden afectar los horizontes políticos de las personas. Su carácter político puede variar mucho, claro. Incluso, lamentablemente, las estructuras de sentimiento pueden manifestar emociones negativas (más adelante, en la cuarta parte de este artículo, retomaré este tema en relación con el populismo). 
Otro vínculo conceptual con el afecto se encuentra en el clásico libro de Negt y Kluge (1993), Esfera pública y experiencia, que escribieron como respuesta crítica al famoso libro de Habermas sobre la esfera pública. Para Negt y Kluge, la esfera pública debería expresar y basarse en los horizontes colectivos de las experiencias vividas por las personas (en vez de solo en la deliberación formal). Esta premisa definió este espacio de formas más receptivas para los individuos de los sectores sociales más bajos. Y precisamente este es el punto de partida de muchos activistas progresistas, quienes, basándose en sus experiencias, generan y participan en esferas públicas alternativas en línea para enfrentarse a las relaciones de poder hegemónicas. En resumen, el afecto se puede considerar como la emocionalidad colectiva dinámica que se conecta con las experiencias sociales compartidas de las personas. El afecto alienta el compromiso y ayuda a motivar la participación. Relacionar la experiencia y el afecto con la realidad empírica requiere, claro, analizar los contextos sociales. El entorno comunicativo donde se encuentran las personas es una característica importante de este contexto social. Observación, esta última, que permite dirigir la mirada a los medios.

\section{LA AMBIVALENCIA DEL ENTORNO EN LÍNEA}

\subsection{El afecto, la sociabilidad y la amistad en línea}

Las diversas plataformas de los medios sociales se vinculan indisolublemente con nuestra vida cotidiana y se usan para numerosos fines. Nuestras experiencias abarcan desdelo administrativo y tedioso hasta lo íntimo y personal, lo social, lo comercial, diversas formas de placer y emoción; juegos y encuentros eróticos excitantes que pueden llevarnos hasta el éxtasis. Las realidades que vivimos en línea se encuentran surcadas por el afecto, como demuestra Highfield (2016). En particular, desde el punto de vista de la participación, las redes sociales y la dimensión emocional de los vínculos juegan un papel fundamental. Las relaciones entre, por un lado, lo personal y lo social y, por el otro lado, lo político, se fomentan más fácilmente. Además, la habilidad de las personas para usar estas plataformas se ha vuelto bastante sofisticada (aunque por supuesto existen patrones de variabilidad social) y en consecuencia contribuye a generar y mantener las esferas públicas.

Asimismo, la capacidad comunicativa de los medios sociales mantiene abierta la posibilidad de que lo político aparezca en las conversaciones (de cualquier tipo). Con nuestra visión esquemática de lo político como realidad emergente en lo discursivo, el acceso a los medios y la interacción con ellos se vuelven obviamente no solo útiles, sino también necesarios para la participación: las personas se vinculan políticamente entre sí, y sostienen ideas y emociones políticas. En sí mismo, el acceso a los medios sociales no convierte a las personas en ciudadanos comprometidos. Aun así, hasta 
donde puede surgir lo político en lo discursivo, Internet y los medios sociales cumplen una función de debate importante en la esfera pública; Facebook en particular. Y en lo que respecta a la coordinación en tiempo real de actividades políticas, el formato acotado de Twitter se ha vuelto invaluable, como destacan diversas investigaciones (Gerbaudo, 2012). En pocas palabras, los medios sociales son recursos cívicos de gran importancia para el compromiso y la participación.

Pero esta visión optimista se enturbia a medida que exploramos las diversas características del entorno en línea. Un tema que ha surgido en la literatura con orientación a la psicología más tradicional (la cual, no obstante, es relevante para la esfera pública) es dónde reside el control: si en la tecnología o en los usuarios. En dicha literatura encontramos una tensión analítica, que reitera muchos de los debates de las décadas anteriores, especialmente aquellos sobre los efectos de la televisión. Algunos autores destacan el potente efecto de los medios digitales sobre cómo vivimos, pensamos, interactuamos con los demás y experimentamos el mundo y a nosotros mismos; y que este efecto es bastante problemático. Aiken (2015), quien se autodenomina "ciberpsicóloga", detecta atributos en los medios digitales que promueven la dependencia, inclusolo que ella llama compulsión y adicción. Cita investigaciones que muestran que, en una encuesta, seis de cada diez encuestados dijeron que "dormían con el teléfono móvil encendido debajo de la almohada o en una mesa de luz junto a la cama" y que "más de la mitad dijeron sentirse incómodos' cuando olvidaban el teléfono móvil en casa" (pp. 61 y 62).

Turkle (2011) argumenta que, muy a menudo, nuestra conexión digital instantánea deriva en soledad emocional. Creemos que podemos forjar relaciones estrechas auténticas sin tener que soportar exigencias ni responsabilidades. Al tiempo que abundan los lamentos filosóficos populares, más especulativos, sobre Internet. Harris (2014), por ejemplo, se apesadumbra por el "fin de la ausencia" y la "pérdida de la falta" que esta conlleva. Es decir, que rara vez nos vemos obligados a pensar, meditar y reflexionar solo con nuestros recursos, sin la asistencia de algún tipo de medio digital. El autor expresa la preocupación que muchos tenemos sobre "usar o perder" algunas de nuestras capacidades humanas más fundamentales. Si bien la evidencia no es concluyente, es muy pronto para descartar estas ideas tan inquietantes sobre nuestra civilización.

En un nivel algo más concreto, el ideal de la amistad también preocupa a algunos investigadores, quienes consideran problemática su evolución en línea. Antes, las amistades eran un asunto generalmente personal y privado. En los medios sociales, se vuelven, en cierto sentido, públicas y funcionan como público de las manifestaciones de nuestra identidad. En consecuencia, cuando las personas escriben en su página de Facebook que llevaron a sus hijos a varias actividades, cuando publican saludos por el Día de la Madre para sus proge- 
nitoras, sucede algo. Por un lado, es fantástico que realicen estas acciones en privado. Al publicarlas en Facebook, las convierten en actuaciones públicas que forman parte de su presentación digital y con las que esperan obtener un "me gusta".

En tal sentido, Bakardieva (2015) rastreó la evolución de la sociabilidad en línea: observa un proceso de racionalización técnica de la amistad. La sociabilidad se convierte en un objeto a computar y adopta formas y gestos cada vez más estandarizados y triviales. La culminación es el surgimiento de los bots sociales: funciones en línea robotizadas que simulan ser amigos. Uno recibe una invitación para agregar a alguien como amigo, pero a menudo esa invitación no proviene de la persona, sino de conclusiones a las que llegó la plataforma mediante algoritmos. ¿Qué efecto tienen estos desarrollos en la amistad y en el afecto en la era digital?

En la obra de autores como Baym (2015) encontramos oposiciones a estas visiones tan pesimistas. Baym resalta el poder del usuario de amoldar los ofrecimientos delos medios a sus propios objetivos. Destacala libertad ganada, sobre todo en nuestras relaciones sociales. Obviamente, hoy en día prácticamente nadie presenta un argumento determinístico unilateral. Más bien se trata de cuáles tendencias consideran dominantes. Sin embargo, existe suficiente evidencia que sugiere que los medios sociales en general, y en particular su contribución al afecto, no carecen de dilemas.

Estas perspectivas pueden parecer algo alejadas de los temas de la esfera pública y la participación, pero debemos tener en cuenta que la intervención política se basa en las relaciones sociales, la identidad y el empoderamiento subjetivo. Comprender la evolución de estos factores en los entornos en línea nos ayudará a analizar el potencial de los medios digitales para favorecer la participación democrática y ser una estructura vital para las esferas públicas.

\subsection{Esferas públicas privatizadas, participación expresiva}

Comprometerse políticamente a través de Internet es ingresar a un entorno comunicativo estructurado por unos pocos actores corporativos enormes, como Google, Microsoft, Facebook y YouTube.La economía política (Franklin, 2013; Fuchs, 2014; van Dijck, 2013) considera a la red como comercial en su esencia (las únicas excepciones son las wikis y otros emprendimientos colaborativos). La realidad básica es que Internet y sus plataformas de medios sociales no excluyen los usos cívicos. Pero, desde el punto de vista del usuario, incluso si tenemos intenciones cívicas o políticas, estamos inmersos y atravesados por discursos consumistas dominantes en línea. Estos discursos posicionan al sujeto principalmente como consumidor, rara vez como ciudadano. Tenemos acceso a un universo casi infinito de consumo, entretenimiento, juegos, deportes, pasatiempos y placeres eróticos. En sí mismo, ninguno de estos dominios es intrínsecamente negativo. Pero, en el contexto de la esfera pública y de la eterna 
competición por la atención, la política sigue siendo un dominio marginal y subordinado en el uso de Internet.

Además, la participación política en línea puede convertirse fácilmente en un habitus privatizado con enfoque consumista (Papacharissi, 2010; Dahlgren, 2013). Los vínculos escasos o inexistentes con otros ciudadanos activos pueden producir una zona de confort cómoda, caracterizada por activismo de sofá (o sillón) y clickactivismo. Intervenir en lo político se convierte implícitamente en una opción de libre elección entre otras actividades recreativas. Esta intervención puede ser bastante agradable y hacernos pasar por alto el trabajo (racional) constante que requiere la participación política seria. Teniendo en cuenta los parámetros de la participación ya mencionados, el modo individual tiene prioridad con respecto al modo colectivo, y el horizonte de compromiso con la sociedad a través de los medios está en riesgo de ser socavado por el compromiso en los medios. Parala participación política en el mundo actual, se necesitan plataformas de medios sociales y otras tecnologías, sin duda. Pero si la participación se reduce solamente a una actividad realizada en privado frente a la pantalla, se pierde mucho de la experiencia de la solidaridad.

Existen otros investigadores que expresaron de manera explícita este argumento. Effler (2010) cita a varios autores que señalan que la participación política interactiva en persona, incluidos los rituales, produce energía emocional y genera y fortalece la identidad colectiva. Los vínculos débiles de las redes son parte integral de la política participativa, pero también se necesitan vínculos fuertes para la actividad política efectiva. Gladwell (2010) también observa que Facebook no genera los vínculos fuertes necesarios para los movimientos sociales. La experiencia de reunirse con otros ciudadanos cara a cara, de compartir el trabajo de organización y movilización, de reírse juntos, de consolarse mutuamente, todo eso fortalece los vínculos entre activistas y genera algo esencial para la agencia política eficaz: solidaridad. Razón por la cual el mundo de la vida real sigue siendo la escena y la fuente esenciales del afecto.

Desde el punto de vista de los parámetros de la participación que ya mencioné, podríamos decir que el peligro yace en que la participación en línea, si bien es fácil de llevar a cabo, tal vez tenga un resultado reducido. Además, los marcos culturales y sociales de esos entornos, es decir las normas y los códigos de interacción en diversas plataformas, podrían inhibir el surgimiento de lo político. La identidad que uno quiere mostrar a sus amigos y el afecto congruente requerido quizá no coincidan con lo que se necesita para el compromiso político (Storsul, 2014). Los contextos codificados culturalmente bien pueden inhibir las conversaciones políticas, tal como ha demostrado Eliasoph (1998).

Por consiguiente, el afecto político en sí mismo no garantiza la eficacia política. De hecho, en general resulta más fácil expresar el afecto propio que plasmarlo mediante acciones. En lo que respecta a la participación, existe 
una dicotomía heurística que surgió con las ciencias políticas tradicionales, al estudiar las motivaciones de los votantes (véase, por ejemplo, Brennan y Lomasky, 1984). Esta dicotomía es relevante en esta discusión: se relaciona con las formas instrumentales y expresivas. En la política instrumental, los ciudadanos están involucrados con las luchas políticas y su resultado. En cambio, en la política expresiva, se considera que el beneficio yace en el acto de expresar las propias opiniones. Es decir, no se prevé ni se exige que la acción tenga consecuencias más allá de la satisfacción que brinda al ciudadano: se "siente bien", uno "se descarga". Esto se nota aún más en el carácter descortés e incluso agresivo de la expresión política en línea: la ira y el odio constituyen gran parte del afecto. Por supuesto, la motivación expresiva puede ser importante para las metas instrumentales a largo plazo al crear identidades colectivas, movilizar la opinión sobre ciertos temas, o generar miedo e intimidación de manera antidemocrática. Pero la distinción continúa teniendo valor heurístico.

En la era de la participación mediada por la red, la expresión a menudo es más fácil de llevar a cabo que la intervención instrumental efectiva en el reino político. En términos sencillos, es más fácil expresar algo que realmente hacer algo. Esto nos conecta con el parámetro del grado de dificultad de la participación. Gran parte de la literatura sobre las esferas públicas, la política e Internet ignora esta distinción. En consecuencia, a la participación expresiva a menudo se le atribuye la misma significación que a las formas instrumentales. Pero así se le resta importancia a la eficacia real. Una excepción es el trabajo realizado por Marichal (2013), quien estudió a 250 grupos de Facebook con orientación política y descubrió que muy pocos alentaban algún tipo de acción. Las publicaciones, sin duda, manifestaban compromiso y constituían formas de participación, pero casi todas en el modo expresivo. Lo cuallleva a establecer que si se evitan sistemáticamente los pasos necesarios para la participación instrumental, se debilita la confrontación con las relaciones de poder. Nuevamente, se materializan los riesgos de que la participación política se convierta en una experiencia cómoda y privada.

\subsection{La línea de tiempo de los medios sociales}

Existen ciertas características del entorno en la red que ya casi no se comentan: se han aceptado como aspectos de sus ofrecimientos positivos. Gilroy-Ware (2017) detalla algunos de estos atributos principales que definen y forman gran parte de nuestra experiencia en los medios sociales. Los organiza en forma de una línea de tiempo afectiva: un despliegue lineal, en su mayor parte cronológico, de los diferentes sitios, tuiteos, publicaciones y noticias que encontramos en nuestras actividades en línea. Esta línea de tiempo incluye las fuentes conocidas que usamos al navegar todos los días, que nos dan sensación de seguridad y confort, y hacen que el presente se devalúe implícitamente a medida que nuestra energía emocional se prepara para prever lo que vendrá a 
continuación; la abundancia de materiales disponibles, que parece ser infinita y proporciona interés y placer sostenidos; la mezcla de distintos elementos que forman la línea de tiempo (la combinación de imágenes, sonidos, géneros, híbridos, música, texto) que observamos y distinguimos principalmente mediante regulación emocional; y la novedad de ofertas, que brinda la imprevisibilidad y la emoción de lo nuevo. Yo también agregaría otra cualidad esencial: la velocidad. La rapidez de movimiento de imágenes, sonidos y texto en la red es una de las características que definen la experiencia en línea.

En lo que respecta específicamente a la abundancia, el contenido de la red es, para los horizontes prácticos de cualquier usuario, aparentemente infinito. Incluso si tratamos de limitar la atención a lo que puede ser relevante para la intervención en la esfera pública (y descartamos la mayor parte del consumo, el entretenimiento, la cultura popular, los pasatiempos, etc.), aun así nos enfrentamos a una cantidad abrumadora de material. Existen diversas variantes de periodismo, actores políticos de todo tipo, corporaciones y otros intereses personales, pero también muchos otros ciudadanos, tanto individuos como grupos cívicos, en sitios web y en medios sociales, que ofrecen información, comentarios, opiniones, debates, rumores, tonterías o información errónea. Lo perspicaz, lo engañoso, lo poético y mucho, mucho más, todo se combina y desdibuja el límite entre el periodismo y lo que no es periodismo, entre lo político y lo que no es político.

Por supuesto, cada uno de nosotros tiene sus propios temas de interés, redes y sitios que sigue, y por lo tanto descarta gran parte de lo que está “ahí fuera” por considerarlo irrelevante. Desarrollamos estrategias personales para lidiar con el tsunami de información diaria; infoglut, como lo llama Andrejevic (2013). Tal como afirma este investigador, incluso si nos limitamos a los temas y a las perspectivas que nos interesan y a los grupos que comparten nuestra visión del mundo, de todas formas a menudo nos enfrentamos a una vasta cantidad de información con vectores discursivos conflictivos.

Por su parte, la novedad y la velocidad son temas clave de la cultura moderna (contemporánea) que muchos escritores han abordado, como Harvey (1991) y Virilio (2002). Puede resultar difícil encontrar y extraer información relevante y confiable en un entorno de información que se mueve rápidamente, y aún más complicado es desarrollar conocimiento. Se requieren tiempo y esfuerzo. Ambos quedan marginados fácilmente en el ambiente de alta velocidad de los medios sociales. Para tomar decisiones, se necesita reflexionar, lo cual requiere tiempo (véase un desarrollo de estos temas en Carr, 2014). El afecto positivo acaba por vincularse con la rapidez y con seguirle el ritmo a las novedades, lo que desvía las exigencias de la intervención racional.

La abundancia y la velocidad aumentan la competencia por la atención. A medida que los entornos de medios se vuelven más densos, la probabilidad de cualquier mensaje de captary mantenerla atención, en general, disminuye. Pett- 
man (2016) argumenta que casi no tiene sentido hablar de distracción cuando la atención se fragmenta tanto: pasamos a una situación caracterizada por la microintervención serial. Asimismo, como plantea Couldry(2014), esto sugiere quelas personas son pocos propensas a comprometerse con temas políticos por periodos prolongados y, mucho menos, con horizontes políticos a largo plazo.

La atención política se orienta más hacialos acontecimientos. El parámetro del periodo de la participación se acorta. Couldry nota que incluso los análisis más rigurosos sobre el modo en que las redes digitales facilitan la participación política, no demuestran que la web fomente el compromiso a largo plazo capaz de producir transformaciones políticas relevantes (véase por ejemplo: Bennett \& Segerberg, 2013). Los resultados han sido, en el mejor de los casos, protestas breves e intensas, como el movimiento Occupy de 2011.

Desde otro ángulo, en la última década han aparecido otros cambios que también transforman los medios sociales como espacios de participación. En ciertos sectores, las discusiones y los debates se han vuelto menos civilizados, más agresivos, especialmente sobre temas que constituyen guerras culturales y conflictos de valores (Nagel, 2017). Si bien aún abundan el humor, la sátira, las bromas y los chistes, vemos un aumento en el discurso del odio contra ciertos grupos, así como acoso a individuos, sobre todo acoso sexual a mujeres, y hasta amenazas de muerte que silencian a ciudadanos, periodistas, figuras públicas y políticos. En consecuencia, la red a veces es un lugar no solo desagradable sino también peligroso, que puede acallar voces de la esfera pública (Phillips \& Milner, 2017). Este desarrollo malintencionado agrega la intimidación a los obstáculos discursivos que uno puede enfrentar y, para la mayoría de los ciudadanos, genera miedo y precaución, a expensas del afecto que fomenta la participación.

Por todo lo dicho y argumentado, Internet, y más específicamente, los medios sociales, ofrecen muchas oportunidades para la participación democrática. Sin embargo, debemos estar alertas a cuáles atributos del entorno digital pueden impedir la participación, sobre todo a qué tipo de afecto promueven implícitamente. Concluiréla discusión situando estas observaciones en el contexto de un desafío concreto al que se enfrenta la democracia en la actualidad: el populismo.

\section{EL DESBORDE: EL POPULISMO YEL AFECTO DEL EXCESO}

Los dilemas alos que se enfrentala democracia son numerosos y profundos. En varias democracias recientes, observamos una tendencia hacia el iliberalismo (Hungría, Polonia), el autoritarismo (Rusia) y hasta la dictadura (Turquía). Globalmente, el capitalismo neoliberal continúa quitando el verdadero poder a los ciudadanos y a las instituciones democráticas y poniéndolo en manos de actores corporativos sin responsabilidad política. De esta forma, socava la de- 
mocracia (Brown, 2015), sus instituciones y su cultura (McGuigan, 2016; Phelan, 2014). Además, se ha observado una reducción de la participación cívica en los procesos políticos delas democracias occidentales durantelos últimos 25 años. Lamentablemente, existen motivos comprensibles para que eso suceda: muchos ciudadanos sienten que el sistema no responde, que los fondos privados compran políticas públicas, que la clase política es indiferente a las voces de los ciudadanos o directamente corrupta (existe una gran cantidad de literatura al respecto; por ejemplo: Hay, 2007). Esto ha debilitado a los partidos políticos como centros de compromiso y participación política, como han notado varios observadores (Mair, 2013). Pero estos desarrollos negativos no están exentos de cuestionamiento, como lo demuestran varios movimientos importantes en los últimos años, entre ellos Occupy y el activismo antiausteridad (Castells, 2012). Sin embargo, en la última década, las democracias occidentales experimentaron otro tipo de respuesta, principalmente de la derecha: el populismo.

\subsection{El problemático populismo}

El populismo es un concepto difícil de precisar, si bien parece que las definiciones se están estabilizando (para ver el abordaje clásico se puede consultar: Cardovan, 1981; otras contribuciones más recientes son: Müller, 2016; Mudde \& Kalhausser, 2017; Wodak, 2013; y en relación con la investigación sobre medios: Alavares \& Dahlgren, 2016). En general, se construye discursivamente a "el pueblo" como unidad virtuosa que se enfrenta a élites malvadas o incompetentes y a "otros" indeseables o peligrosos (como minorías raciales y religiosas, intelectuales, periodistas o gobiernos). El rol de las grandes corporaciones a menudo es ambiguo. Se apela afectivamente a que "el pueblo" (por supuesto, esta categoría excluye a ciertos grupos) recupere lo que perdió. Y a veces se exhorta a los ciudadanos a participar violando procedimientos constitucionales en nombre del "gobierno del pueblo". En los Estados Unidos, la campaña presidencial, la presidencia y los partidarios de Donald Trump constituyen un ejemplo elaborado.

Estos desarrollos son sumamente problemáticos, ya que son producto de las falencias genuinas de la democracia liberal, es decir, sus promesas incumplidas. "Las prácticas populistas surgen a partir del fracaso de las instituciones sociales y políticas para confinar y regular a los sujetos políticos dentro de un orden social relativamente estable" (Panizza, 2005, p. 9). Diversos grupos se sienten excluidos en forma social, política y cultural; perciben que no se los reconoce y sienten resentimiento. Hoy en día, el populismo de derecha varía ideológicamente: desde la centroderecha casi convencional hasta los extremos de la xenofobia, el nacionalismo militante, el racismo y el protofascismo ${ }^{3}$. La negativa de escuchar y la incapacidad de producir cambios de los políticos

3 Puede decirse que, en la actualidad, los neonazis son demasiado marginales para tener atractivo populista. 
convierten a los ciudadanos comprometidos en ciudadanos furiosos. El afecto a menudo es intenso.

Sin duda, la ira y, en el fondo, el miedo, son el combustible del populismo. En el panorama actual de los medios, los grupos pueden mantenerse cada vez más dentro de sus propias esferas contra públicas, cámaras de eco, aisladas de visiones contrarias, y cultivar el discurso grupal sin tener que participar en debates racionales (Sunstein, 2017). Muchos grupos y partidos populistas occidentales han seguido esta tendencia hasta el extremo, pudiendo incluso crear en forma afectiva un sentido de propósito e identidad colectiva. Los recursos disponibles (a menudo amplios), los esfuerzos de organización y el fuerteliderazgo pueden contribuir con la participación a largo plazo.

En estos enclaves discursivos, no solo se moviliza la emocionalidad relacionada con las opiniones políticas. Cada vez más, se afianzan visiones alternativas de la realidad. El conocimiento sobre el mundo compartido por la sociedad comienza a desintegrarse. Entramos en la era de la postverdad (el término en inglés, post-truth, fue la palabra del año 2016 elegida por el Diccionario de Oxford). El ataque en parte se dirige al periodismo convencional, que ya es una institución debilitada en lo que respecta a producción del conocimiento, con incertidumbre cada vez mayor sobre su posición y su rol (véase, por ejemplo, Alexander et al., 2016). Las acusaciones de noticias falsas (fakenews), informes sesgados, desinformación, etc. se han vuelto frecuentes. También se ataca a la ciencia, a las universidades, a los tribunales y a los expertos en general (un ejemplo es la negación del cambio climático), en muchos casos aferrándose a discursos teológicos como oposición a la evidencia empírica. La opinión se coloca en una posición a la par del conocimiento basado en hechos.

Aquí lo significativo no es solo la indiferencia hacia la determinación de la verdad, sino el rol del afecto en este contexto epistemológico. Fernández-Armesto (2010) sugiere que, históricamente, existen cuatro métodos o procedimientos básicos que usamos para determinar qué es verdad: lo que sentimos, lo que nos dicen, lo que podemos deducir y lo que observamos empíricamente. En cualquier momento de la historia, los cuatro coexisten y se relacionan entre sí de diversas formas. Hoy en día, en el mundo viral de la información en línea, claramente se está imponiendo la primera opción, lo que sentimos. La verdad se reconfigura como realidad subjetiva interna, un salto afectivo, y por lo tanto se convierte en la base de las afirmaciones de validez sobre la realidad. La argumentación racional se convierte aún más en un modo discursivo inconmensurable.

Claro que esta es una representación extrema, pero captura una importante tendencia actual. Resulta fácil que las presuposiciones de los ciudadanos, combinadas con un sentido débil dela eficacia, tengan más fuerza psicológicamente que el razonamiento crítico. El afecto puede llevar a las personas a encontrar atajos para lidiar con la enorme cantidad de información con la que se enfren- 
tan a alta velocidad. La disonancia cognitiva se reemplaza por la comodidad cognitiva, a través dela emoción. Además, la fuerza de gravedad dela identidad grupal reduce la inseguridad social y promueve los lazos grupales afectivos, y así refuerza este camino hacia el conocimiento. A largo plazo, esto debilita al individuo, fomenta la limitación cognitiva de los grupos y, finalmente, perjudica el rol crítico de las esferas públicas.

Cuando se habla sobre populismo, a menudo se destaca, justificadamente, cómo este apela a las emociones de los ciudadanos y puede lograr movilizarlos. Sin embargo, debemos tener en cuenta, como ya he mencionado, que toda la política (incluida la política partidaria más tradicional) requiere una dimensión de la emoción individual y el afecto colectivo para motivar la participación. Afirmaría que, de hecho, toda la política democrática debe ser "popular" hasta cierto punto, en el sentido de obtener apoyo a través de la intervención afectiva. Lo popular puede convertirse fácilmente en populismo, aunque los criterios han variado según el momento y el lugar. Por lo tanto, a veces puede costarnos determinar el límite, si bien el populismo "duro" en general tiene el componente de "nosotros contra ellos", que incluye la búsqueda de chivos expiatorios. El discurso político y el periodismo convencionales tal vez eviten la polarización social del auténtico populismo, pero igualmente pueden caer en modos discursivos post-racionales y promover la opinión por sobre el análisis factual, sobre todo en los géneros más amarillistas: el infoentretenimiento existe desde hace mucho tiempo y el equilibrio productivo entrela razón yla emoción es precario y fácil de desestabilizar.

A fin de cuentas, como ciudadanos democráticos debemos luchar no solo por las causas y los temas en los que creemos (y a los que investimos de afecto), sino también por el carácter de la democracia. Actualmente, ello parece necesitar de mucho apoyo.

\section{REFERENCIAS}

Aiken, M. (2017). The Cyber Effect. York: Random House.

Alexander, J., Breese, E. \& Luengo, M. (edits.) (2016). The Crisis of Journalism Reconsidered: From Technology to Culture. Basingstoke: Palgrave.

Alvares, C. \& Dahlgren, P. (2016). Populism, extremism, and media: Mapping an uncertain terrain. European Journal of Communication, 31, 46-57.

Andrejevic, M. (2013). Infoglut: How Too Much Information is Changing the Way we Think and Know. Abingdon: Routledge.

Bakaedjieva, M. (2015). Rationalizing sociality: an unfinished script for socialbots. The Information Society: An International Journal, 31, 244-256. DOI: 10.1080/01972243.2015.1020197 
Baym, N. K. (2015). Personal Connections in the Digital Age 2nd ed. Cambridge: Polity Press.

Bennett, W. L. \& Segerberg, A. (2013). The Logic of Connective Action:Digital Media and the Personalization of Contentious Politics. New York: Cambridge University Press.

Brennan, G. \& Lomasky, L. (1984). Democracy and Decision. New York: Cambridge University Press.

Brown, W. (2015). Undoing the Demos: Neoliberalism's Stealth Revolution. Cambridge, MA y London: MIT Press.

Canovan, M. (1981). Populism. London: Junction.

Carpentier,N.(2011). Mediaand Participation: A Site ofIdeological-DemocraticStruggle. Bristol: Intellect Publishers.

Carr, N. (2014). The Glass Cage: How Our Computers are Changing Us. New York: Norton.

Castells, M. (2012). Networks of outrage and hope: Social movements in the Internet age. Cambridge: Polity Press.

Coleman, S. (2014), How Voters Feel. Cambridge: Cambridge University Press.

Couldry,N.(2014). Themythof' us': digitalnetworks, politicalchangeand theproduction of collectivity. Information, Communication \& Society, 18(6), 235-249.

Couldry, N., \& Hepp, A. (eds.) (2013). Conceptualizing mediatization. Communication Theory, 23(3), 608-626

Couldry, N. \& Hepp, A. (2016). The Mediated Construction of Reality. Cambridge: Polity Press.

Couldry, N., Livingstone, S. \& Markham, T. (2010). Media Consumption and Public Engagement: Beyond the Presumption of Attention. Basingstoke: Intellect.

Crary, J. (2013). 24/7 Late Capitalism and the Ends of Sleep. London: Verso.

Dahlberg, L. (2014). The Habermasian public sphere and exclusion: an engagement with poststructuralist-influenced critics. Communication Theory, 24(1), 21-41.

Dahlgren, P. (2013). The Political Web:Participation, Media, and Alternative Democracy. Basingstoke, UK: Palgrave Macmillan.

Dahlgren, P. (2009). Media and Political Engagement: Citizens, Communication, and Democracy. New York: Cambridge University Press.

Effler, E. (2010). Laughing Saints and Righteous Heroes: Emotional Rhythms in Social Movement Groups. Chicago: University of Chicago Press. 
Eliasoph, N. (1998). Avoiding Politics: How Americans Produce Apathy in Everyday Life. Cambridge: Cambridge University Press.

Elliott, A. (2008). Concepts of the Self. Cambridge: Polity Press.

Fenton, N. (2016). Digital, Political, Radical. Cambridge: Polity Press.

Fernández-Armesto, F. (2010). Truth: A History and Guide for the Perplexed. London: Black Swan.

Franklin, M.I. (2013). Digital Dilemmas: Power, Resistance, and the Internet. Oxford: Oxford University Press.

Frosh, S. (2011). Feelings. Abingdon: Routledge.

Fuchs, C. (2014). Social Media: An Introduction. London: Sage.

Gerbaudo, P. (2012). Tweets and the Streets: Social Media and Contemporary Activism. London: Verso.

Gilroy-Ware, M. (2017). Filling the Void:Emotion, Capitalismand Social Media. London: Repeater Books.

Gladwell, M. (2010).Small change: Why the revolution will not be tweeted. New Yorker, 4 de octubre. Retrieved: 27/2/2015. Available at: http://www.newyorker.com/ reporting/2010/10/04/101004fa_fact_gladwell

Gregg, M. \& Seigworth, G. J. (eds.) (2010).The Affect Theory Reader. North Carolina: Duke University Press.

Habermas, J. (1989). Structural Transformation of the Public Sphere. Cambridge: Polity Press.

Hall, C. (2005). The Trouble with Passion: Political Theory Beyond the Reign of Reason. New York: Routledge.

Harris, M. (2014).The EndofAbsence: Reclaiming What We've Lost in a World of Constant Connection. New York: ACTUAL/Penguin.

Harvey, D. (1991). The Condition of Post-Modernity. Oxford: Blackwell.

Hay, C. (2007). Why We Hate Politics. Cambridge: Polity Press.

Hepp, A. (2013). Cultures of Mediatization. Cambridge: Polity.

Highfield, T. (2016). Social Media and Everyday Politics. Cambridge: Polity Press.

Hjarvard, S. (2013). The Mediatization of Culture and Society. London: Routledge.

Lundby, K.(ed.) (2014).Mediatization ofCommunication:Handbooks ofCommunication Science, 21. Berlín: De Gruter Mouton. 
Lunt, P. y Livingstone, S. (2016). Is mediatization the new paradigm for our field? Media, Culture \& Society, 38(3), 462-470.

Mair, P. (2013). Ruling the Void: The Hollowing of Western Democracy. London: Verso.

Margetts, H., Scott, P. \& Yasseri, T. (2016). Political Turbulence: How Social Media Shape Collective Action. Princeton: Princeton University Press.

Marichal, J. (2013). Political Facebook groups: Micro-activism and the digital front stage. First Monday, 18(12). Retrieved:22/1/2017 Available at: http://firstmonday. org/ojs/index.php/fm/article/view/4653/3800

Massumi, B. (2002). Parablesforthe Virtual: Movement, Affect, Sensation. Durham:Duke University Press.

McGuigan, J. 2016). Neoliberal Culture. Basingstoke: Palgrave.

Morozov, E. (2011). The Net Delusion: How Not to Liberate the World. London: Allen Lane.

Mouffe, C. (2013). Agonistics: Thinking the World Politically. London: Verso.

Mudde, C. \& Kalhausser, C. (2017). Populism: A Short Introduction. Oxford: Oxford University Press.

Müller, J.W. (2016). What is Populism? Filadelfia: University of Pennsylvania Press.

Nagle, A. (2017). Kill All Normies. London: Zero Books.

Negt, O. \& Kluge. A. (1993). The Public Sphere and Experience. Minneapolis: University of Minnesota Press.

Panizza, F. (2005). Introduction. En F. Panizza, F. (ed.). Populism and the Mirror of Democracy (pp. 1-31). London: Verso.

Papacharissi, Z. (2010). A Private Sphere: Democracy in a Digital Age. Cambridge: Polity Press.

Papacharissi, Z. (2014). Affective Publics: Sentiment and the New Political. New York: Oxford University Press.

Papacharissi, Z. (2015). Towards new journalism(s):affective news, hybridity, and liminal spaces. Journalism Studies, 16(1), 27-40.

Pettman, D. (2106). Infinite Distraction: Paying Attention to Social Media. Cambridge: Polity.

Phelan, S. (2014). Neoliberalism, Media and the Political. Basingstoke: Palgrave.

Phillips, W. \&Milner, R. (2017). The Ambivalent Internet: Mischief, Oddity, and Antagonism Online. Cambridge: Polity Press. 
Storsul, T. (2014). Deliberation or self-presentation? Young people, politics and social media. Nordicom Review, 35(2), 17-28.

Sunstein, C. (2017).\#Republic: Divided Democracy in the Age of Social Media. Princeton: Princeton University Press.

Turkle, S. (2011). Alone Together: Why We Expect More from Technology and Less from Each Other. New York: Basic Books.

Turner, G. (2002). British Cultural Studies. London: Routledge.

van Dijck, J. (2013). The Culture of Connectivity: A Critical History of Social Media. Oxford, UK: Oxford University Press.

van Zoonen, L. (2005). Entertaining the Citizen: When Politics and Popular Culture Converge. Lanham, MD: Rowman \& Littlefield.

Virilio, P. (2000). The Information Bomb. London: Verso.

Wodak, R., Khosravinik, M. \& Mral, B. (eds.) (2013). Right-Wing Populism in Europe: Politics and Discourse. London: Bloomsbury.

\section{IDENTIFICACIÓN DEL AUTOR}

Peter Dahlgren es profesor emérito en el Departamento de Comunicaciones y Medios de la Universidad de Lund, Suecia. En sus trabajos recientes - loslibros The political web:media, participation andalternative democracy (2013), el volumen Young People, ITSc and Democracy (2010), del que fue coeditor, y Media and PoliticalEngagement (2009), así como artículos publicados en revistas académicas-abordó Internet y la participación política, examinando las identidades y el compromiso cívico. Participa activamente en redes académicas europeas: ha sido profesor invitado en varias universidades, en cuyo marcoha realizado actividades en: European Cooperation in Sciene \& Technology (COST), European Science Foundation, The European Network for Doctoral Studies in Communication and Media, entre otras. Realizó trabajos como profesor invitado en Francia (Université Paris 2, Université Paris 3, Université Grenoble 3), Escocia (University of Stirling), Sudáfrica (Rhodes University), Canadá (l'Université du Québec) y Estados Unidos (University of Pennsylvania).

\section{REGISTRO BIBLIOGRAFICO}

Dahlgren, P. (enero-junio, 2018). La participación en línea en la esfera pública. Las ambigüedades del afecto. InMediaciones de la Comunicación, 13(1), 25-47 